\title{
Conhecimento sobre a presença da filmadora, níveis de ansiedade e desempenho motor global de crianças
}

http://dx.doi.org/10.11606/1807-5509201700040857

\author{
Fabiana Monteiro BASSI ${ }^{*}$ \\ Flávio de Souza CASTRO** \\ Luciano BASSO ${ }^{* * * *}$ \\ Jaqueline Freitas Oliveira NEIVA* \\ Cassio de Miranda MEIRA JUNIOR* \\ *Escola de \\ Artes, Ciências \\ e Humanidades, \\ Universidade de São \\ Paulo, São Paulo, SP \\ Brasil. \\ ${ }^{* *}$ Universidade \\ Federal do Rio \\ Grande do Sul, Porto \\ Alegre, RS, Brasil. \\ ***Escola de \\ Educação Física e \\ Esporte, Universidade \\ de São Paulo, São \\ Paulo, SP, Brasil.
}

\section{Resumo}

A presente pesquisa teve como objetivo investigar o efeito do conhecimento sobre a presença da filmadora no desempenho de habilidades motoras fundamentais e a relação com os níveis de ansiedade em crianças. Participaram da pesquisa 31 crianças do sexo masculino, com idades entre 7 e 9 anos, as quais executaram seis habilidades motoras de locomoção e seis de controle de objeto do Teste de Desenvolvimento Motor Global 2 em duas situações, com a filmadora visivel e com a filmadora oculta. 0 questionário de ansiedade traço-estado para crianças de Spielberger foi utilizado para medir os níveis de ansiedade antes e durante a realização do teste motor. Cada criança foi testada nas duas condições, com intervalo de três meses entre os momentos de coleta. Os testes $t$ de Student para amostras dependentes indicaram desempenhos superiores para a condição de filmadora visivel no subteste controle de objeto e no coeficiente motor geral. Em ambas as condições, o teste de qui-quadrado apontou que a maioria das crianças apresentou nível "muito pobre" de desenvolvimento motor global. Não foram encontradas correlações significativas entre ansiedade e desempenho motor. Os achados foram discutidos com base em teorias de motivação para o desempenho, fundamentalmente sobre aspectos relacionados à autodeterminação, fluxo e nível de ativação.

Palavras-Chave: Habilidade Motora; Ansiedade; TGMD-2; Crianças.

\section{Introdução}

As pesquisas que enfocam a avaliação do domínio motor na infância têm sido bastante frequentes no Brasil ${ }^{1-3}$ e no exterior ${ }^{4,5}$. O TGMD-2 ${ }^{6}$ é um dos instrumentos mais utilizado para mensurar o desenvolvimento motor global de crianças, considerando habilidades motoras típicas da fase de movimentos fundamentais (ex: correr, saltar, arremessar, chutar, rebater) ${ }^{7}$.

Uma temática de pesquisa específica neste contexto diz respeito a alteraçôes de desempenho de crianças que apresentam alguma característica psicológica particular ${ }^{8-11}$. A síntese dos resultados desses estudos sugere a relação entre desempenho motor e percepção de competência, motivação intrínseca, traços de personalidade e estresse. As crianças apresentaram desempenhos abaixo ou muito abaixo da norma e demonstraram níveis moderados de percepção de competência e de motivação intrínseca; nessa última variável, as crianças mais velhas tendem a demonstrar maiores níveis. Outro resultado importante é que os meninos se mostraram melhores do que as meninas em ambas as classes de movimento (locomoção e controle de objeto), bem como na motivação intrínseca e na percepção de competência. 
O baixo desempenho apresentado por crianças brasileiras em testes motores como o TGMD-2 desperta questóes e abre diferentes suspeitas. Dentre elas, de que o baixo desempenho pode estar relacionado à formalidade do protocolo no momento de aplicação. Ou seja, a ideia do presente estudo é que a formalidade da avaliação motora pode ser um fator causador de alteraçóes (positivas ou negativas) no desempenho de quem a executa, e as razóes pelas quais isso ocorre podem ser tanto ambientais quanto pessoais.

A presença de avaliadores e equipamentos (p.ex., a filmadora) no ambiente de coleta, bem como características emocionais dos executantes são fatores candidatos a desencadear efeitos distintos no desempenho do TGMD-2. Com o intuito de conferir mais qualidade aos dados, há uma orientação no manual do teste para que a realização das tarefas seja gravada para posterior análise. Por si só essa gravação já poderia ser apontada como possível fator desencadeador de mudança no desempenho. Mais além, o impacto desse fator pode ainda ser maior ou menor dependendo do estado ou traço emocional do executante. Por exemplo, pessoas com diferentes níveis de ansiedade podem ter desempenhos motores distintos ${ }^{12-15}$. Para SPIelberger ${ }^{16}$ indivíduos muito ansiosos respondem a situaçóes de ameaça percebida com reaçóes desproporcionais ao perigo real quando comparados a indivíduos pouco ansiosos. Porém, apesar de alta ansiedade estar frequentemente relacionada ao desempenho negativo em tarefas $\operatorname{cognitivas}^{17,18}$, não há evidências deletérias de alta ansiedade no desempenho motor ${ }^{19}$.

O estudo foi concebido com o intuito de estudar um fator de formalidade de testagem, o desempenho dos sujeitos testados e suas características emocionais. Para tanto, procurou-se investigar em crianças escolares o efeito no desempenho motor e na ansiedade do conhecimento sobre a presença de filmadora no ambiente de aplicação do TGMD-2. O objetivo primário foi identificar o efeito que a informação acerca da presença da filmadora no ambiente de coleta apresenta no desempenho do teste. O objetivo secundário foi investigar se há relaçóes entre os escores do TGMD-2 das duas situaçôes supracitadas e os escores de ansiedade (traço e estado) avaliados pelo questionário IDATE-C. A hipótese testada foi que o conhecimento sobre a presença da filmadora provoca menores escores no TGMD-2 ${ }^{8-11}$, independentemente dos níveis de ansiedade ${ }^{17-19}$.

\section{Método}

\section{Participantes}

Trinta e uma crianças foram designadas por conveniência a um grupo único de pesquisa. Todas do sexo masculino, com idades entre sete e nove anos $(8,5 \pm 0,8$ anos - de acordo com o informado no TCLE), estudantes do ensino fundamental de duas escolas da rede pública do Estado de Minas Gerais. Os participantes não possuíam experiência na execução do protocolo do TGMD-2.

Os responsáveis legais dos participantes preencheram um termo de consentimento livre e esclarecido, contendo informaçóes detalhadas sobre os procedimentos e riscos da pesquisa, bem como de seus direitos como participantes de um experimento com fins científicos. O estudo foi aprovado pelo Comitê de Ética em Pesquisa da Universidade dos pesquisadores principais CAAE 0030.0.468.000-11

\section{Instrumento e teste}

O teste motor utilizado foi o TGMD $-2^{6}$, composto por 12 habilidades motoras, seis de locomoção e seis de controle de objeto. De acordo com a indicação do protocolo de aplicação do teste, utilizou-se uma filmadora para registrar a execução das habilidades. As habilidades avaliadas foram: correr, galopar, saltitar, saltar obstáculo, saltar horizontalmente e deslizar (locomotoras) e rebater uma bola estacionária, quicar, receber, chutar, arremessar por cima do ombro e rolar a bola por baixo do ombro (controle de objeto). A aplicação do teste foi realizada com cada criança individualmente, na presença de dois avaliadores, um forneceu instrução e demonstração e outro executou a filmagem. As avaliaçóes seguiram a ordem do protocolo e a aplicação com cada criança durou aproximadamente 20 minutos. Todos os 
procedimentos de condução do teste seguiram as recomendaçôes descritas por $\mathrm{ULRICH}^{6}$, conforme os itens a seguir: a) o teste foi aplicado em um ambiente apropriado para a realização das atividades (quadra poliesportiva ampla e com iluminação suficiente); b) solicitou-se à criança que ouvisse, com bastante atenção, as instruçóes e demonstraçóes que foram fornecidas pelo pesquisador; c) antes de a criança executar as duas tentativas de cada uma das doze habilidades, o pesquisador forneceu as instruçóes e efetuou uma demonstração; se necessário (quando o pesquisador julgava que o desempenho foi insatisfatório), o mesmo processo foi repetido depois da primeira tentativa; d) em nenhuma tentativa as crianças receberam "feedback" extrínseco, em forma de conhecimento de desempenho ou de resultado; e) cada criança foi instruída a realizar uma tentativa de ensaio para assegurar que compreendeu a tarefa. O TGMD-2 apresenta indicadores de validade de conteúdo e constructo adequados à população brasileira $^{7}$. No entanto, como não há estudos que apresentem indicadores de validação das normas a populaçáo brasileira, optou-se em utilizar tanto os valores brutos dos escores das subescalas, quanto os níveis de desenvolvimento - sabendo da limitação destes últimos.

$\mathrm{O}$ instrumento para avaliação da ansiedade foi o Inventário de Avaliação Infantil de Ansiedade Traço e Estado (IDATE-C), adaptado de BIAGgio e SPIELBERger ${ }^{20}$. Esse inventário é auto-aplicável e composto por duas subescalas distintas que mensuram a ansiedade-estado (A-e) e a ansiedadetraço (A-t). A validade do inventário baseia-se na certeza de que o avaliado tenha uma boa compreensáo das afirmaçóes descritas na folha de teste. Para que isso ocorresse da melhor forma possível, um avaliador treinado e capacitado acompanhava cada criança no preenchimento das questôes, em uma sala ao lado da quadra, sem a presença das demais crianças.

A subescala de (A-e) pretende medir estados transitórios de ansiedade, isto é, sentimentos subjetivos, conscientemente percebidos de apreensão, tensão e preocupaçáo que variam em intensidade e flutuam no tempo, ou seja, como a criança se sentia no exato momento da aplicação do questionário. A subescala de (A-t) objetiva medir diferenças individuais relativamente estáveis em susceptibilidade à ansiedade, ou seja, como a criança se sente de um modo geral ${ }^{20}$. Cada sub-escala possui vinte afirmaçôes impressas em cadernos separados e, para respondêlas, o indivíduo realiza um autorrelato de acordo com uma escala de três pontos: 1 - Quase nunca;
2 - Às vezes; 3 - Muitas vezes (A-t); e 1 - Eu me sinto muito...; 2 - Eu me sinto...; 3 - Eu não me sinto... (A-e). O inventário foi aplicado em dois momentos: antes da aplicação do TGMD-2 nas duas situaçóes de filmadora (visível e oculta) em ambas as escalas (A-t e A-e) e entre as habilidades de locomoção e de controle de objeto (A-e).

\section{Material e equipamento}

O questionário IDATE-C foi impresso em quatro folhas e as crianças preencheram-no com lápis e borracha. Na aplicação do TGMD-2 foram utilizados: a) para marcaçóes no chão - mapa para montagem, rolo de fita crepe, caneta hidrográfica com ponta grossa, trena e quatro cones; b) para a filmagem - tripé, filmadora digital (Marca Sony) e cartóes de memória; c) para a execução das habilidades - claquete (identificação da criança), obstáculos, cone e haste (base para a rebatida) e bolas; d) para a identificação da criança - crachás; e) para oclusão da filmadora - biombo de papeláo com uma abertura central para a colocação da filmadora na situação oculta.

\section{Desenho experimental e procedimentos}

A coleta de dados envolveu cada criança participar de duas situaçôes experimentais com intervalo de três meses entre as situações. $\mathrm{Na}$ situação de filmadora oculta (FO), a criança não foi informada que a filmadora estava presente de modo que houve ocultação do equipamento de filmagem atrás de um biombo - a filmadora manteve-se escondida entre outros materiais de pesquisa. Na situação de filmadora visível (FV), a criança teve conhecimento sobre presença da filmadora no ambiente de coleta, inclusive com os pesquisadores indicando o local onde estava situado o equipamento de filmagem (por meio de informaçáo verbal reforçando que a filmadora estava presente e visível).

Para a execução do TGMD-2, cada criança foi posicionada ao lado do pesquisador principal, momento em que recebeu informaçóes detalhadas sobre como executar cada tarefa do teste. Cada criança executou duas tentativas em cada tarefa motora. Antes de cada tarefa-alvo, a pesquisadora forneceu descrição verbal e demonstração precisa sobre a execuçâo. Caso a criança demonstrasse insegurança na execução do movimento ou não o realizava, outra demonstração adicional foi fornecida. 
Para minimizar a ameaça à validade interna "efeito da testagem"21, na primeira coleta de dados $(\mathrm{C} 1), 16$ crianças foram testadas na situação $\mathrm{FO}$ e 15 crianças na situação FV. Na segunda coleta de dados (C2), essa ordem foi invertida.

As coletas de dados ocorreram em salas de aula e quadras poliesportivas das escolas. Cada coleta obedeceu a seguinte ordem: a) responder ao Questionário IDATE-C (A-e e A-t); b) executar seis habilidades motoras de locomoção (TGMD-2); c) responder ao Questionário IDATE-C (A-e); e d) executar seis habilidades motoras de controle de objeto.

No D1 da coleta 2 (C2), dezesseis crianças responderam, individualmente, sob orientaçáo dos pesquisadores, uma ficha com dados pessoais (nome, idade, escola e série) e o IDATE-C em uma sala de aula vazia. Então cada criança foi encaminhada à quadra para tomar parte no teste TGMD-2 na situação FO. No segundo dia (D2) da (C1), outras quinze crianças foram submetidas aos mesmos procedimentos, porém na situação FV. Passados três meses, os mesmos procedimentos foram aplicados nas mesmas 31 crianças, porém em ordem invertida de situaçóes. No primeiro dia (D1) da coleta 2 (C2), o grupo de 16 crianças (D1-C1) foi testado na condição FV, de modo que quem não sabia da presença de filmadora no $\mathrm{D} 1 \mathrm{da} \mathrm{C} 1$ passou a saber no D1 da C2. No segundo dia da C2, o grupo de 15 crianças (D2-C1) foi testado na condição FO, de modo que quem viu a filmadora no D2 da C1 passou a não vê-la no D1 da C2. Portanto, quem náo sabia da presença da filmadora na primeira coleta, passou a saber na segunda coleta e quem sabia da presença da câmera na primeira coleta, passou a náo a ver na segunda coleta. Nesse último caso, nenhum procedimento verbal específico foi utilizado pelos pesquisadores para avisar a criança sobre isso, tampouco nenhuma criança perguntou sobre a existência da filmadora.

\section{Organização e análise de dados}

Os dados foram obtidos das duas situações e organizados em planilhas eletrônicas. Os valores considerados na análise foram os escores (somatório de critérios para cada classe de movimento e níveis de desenvolvimento motor) nas duas situaçóes do TGMD-2 e do IDATE-C. Cada criança, portanto, obteve em cada situaçáo o seguinte conjunto de valores: a) Somatório de critérios da classe de movimento locomotor do TGMD-2 (variando de
0 a 48 critérios); b) Somatório de critérios da classe de movimento de controle de objetos do TGMD-2 (variando de 0 a 48 critérios); c) Quociente motor global do TGMD-2; d) IDATE-C (AnsiedadeEstado Inicial); e) IDATE-C (Ansiedade-Traço); f) IDATE-C (Ansiedade-Estado Média).

A análise de vídeo das habilidades do TGMD-2 foi realizada por uma equipe de pesquisadores com experiência em outros projetos de pesquisa que utilizaram o mesmo teste ${ }^{22,23}$ (apresentaram nível de confiança superior a 0,85 para cada variável analisada). As análises foram realizadas com base no manual do examinador ${ }^{6}$, seguindo o protocolo do teste e os critérios de desempenho das habilidades motoras. A atribuição dos vídeos foi organizada pelo método cego ${ }^{24,25}$, de modo que o examinador não sabia qual situação (FO ou FV) estava avaliando.

Cada habilidade motora inclui vários componentes comportamentais que são apresentados como critério de desempenho. Se a criança desempenha um componente, o examinador marca " 1 "; se a criança não desempenha o examinador marca "0". Após completar esse procedimento para cada uma das duas tentativas, o examinador totaliza o escore obtido nas duas tentativas para obter um escore bruto da habilidade em cada item (correr, galopar, saltar, chutar, arremessar). Os escores das habilidades são somados a um escore bruto do subteste (locomotor e controle de objeto), o qual é convertido a um escore padrão, quando no final o escore padrão do subteste é combinado e convertido ao Quociente Motor Grosso Geral (Coeficiente Motor). As etapas de cálculo são: a) soma do escore das duas tentativas de cada habilidade para cada classe de movimento = escore bruto da classe locomotora e controle de objeto; b) decodificação de cada escore bruto em percentis de acordo com a norma para sexo e idade = percentil para cada subteste; c) somatório dos percentis; d) decodificação na escala do coeficiente motor. No total, foram avaliados 1488 vídeos de habilidades motoras, pois houve duas coletas com cada uma das 31 crianças executando duas vezes as 12 habilidades.

No IDATE-C, os itens em que o termo-chave indica a presença de ansiedade, "muito" e "não" recebem os valores de 3 e 1 , respectivamente. A ordem dos pesos é invertida para itens em que os termos-chave indicam a ausência de ansiedade, isto é, "muito" = 1; "não" = 3. O valor 2 é atribuído a todas as respostas em que a criança assinala apenas o adjetivo. Por exemplo, "muito nervoso" = 3; "nervoso" = 2; e "não me sinto nervoso" = 1; e "muito calmo" = 1 ; 
"calmo" = 2; e "não me sinto calmo" = 3. Itens indicadores da ausência de ansiedade, que são avaliados no sentido 1, 2 e 3 são os seguintes: 1, 3, $6,8,10,12,13,14,17,20$. Nos restantes, "muito" é avaliado como 3 e "não" como 1 . Os escores podem variar de um mínimo de 20 pontos até um máximo de 60 pontos.

No que se refere à análise estatística, primeiramente, os dados foram explorados por meio de análise descritiva, baseada em medidas de tendência central e testes de hipóteses quanto a distribuição (teste de Shapiro-Wilk). Então os dados foram submetidos a análises inferenciais com o intuito de verificar a existência de diferenças significativas entre as duas situaçóes por meio do teste $\mathrm{t}$ Student para amostras dependentes, e a magnitude e direção das correlaçóes entre os escores por meio da matriz de correlaçóes de Pearson (r). A normatização dos valores de desempenho no TGMD-2 sugerida pelo manual ${ }^{6}$ foi alvo de interesse, bem como a comparação entre as frequências dos níveis do coeficiente motor nas duas condiçôes, os quais foram analisados por meio do teste de aderência de qui-quadrado.

\section{Resultados}

A inspeção inicial dos resultados indicou, em todas as variáveis de análise, ausência de dados faltosos, ausência de outliers severos e a presença de normalidade na distribuição dos valores.

Os valores da estatística descritiva referentes às variáveis de interesse são apresentados na TABELA 1. Os testes $\mathrm{t}$ Student indicaram diferenças significativas entre as duas condições, com superioridade para a condição FV nas variáveis "coeficiente motor global" $[\mathrm{t}(30)=2,97$; $\mathrm{p}=0,006]$ e "controle de objeto" $[\mathrm{t}(30)=3,93$; $\mathrm{p}=0,0001]$. Para a variável "locomoção", o teste não detectou diferença significativa $[\mathrm{t}(30)=1,58$; $\mathrm{p}=0,126]$.
As correlaçóes de Pearson entre os valores obtidos no questionário de ansiedade (IDATE-C) e o desempenho no TGMD-2 (coeficientes geral, locomoçáo e controle de objeto) nas duas condiçôes foram calculadas de modo que a matriz dos valores pode ser visualizada na TABELA 2. Foram identificadas correlaçóes significativas apenas no conjunto de variáveis de ansiedade e no conjunto de variáveis de desempenho motor. Todavia, não foram encontradas correlaçóes significativas entre variáveis de ansiedade e de desempenho motor. As correlaçóes detectadas ocorreram apenas no seio de variáveis de ansiedade e no seio de variáveis de desempenho - o que era previsto pela literatura de ambos os assuntos.

TABELA 1 - Médias (X்) e desvios-padrão (DP) nas variáveis de interesse para a condição de Filmadora visível (FV) e oculta (FO).

\begin{tabular}{lcc}
\hline \multirow{2}{*}{ Variáveis } & \multicolumn{2}{c}{ Filmadora } \\
\cline { 2 - 3 } & FV & FO \\
\cline { 2 - 3 } & X + DP & X+DP \\
\hline Ansiedade Estado Inicial (AEI) & $31,58 \pm 4,18$ & $31,26 \pm 3,40$ \\
\hline Ansiedade Traço Inicial (ATI) & $33,39 \pm 3,96$ & $33,32 \pm 5,40$ \\
\hline Ansiedade Estado Média (AEM) & $30,29 \pm 3,56$ & $31,10 \pm 4,20$ \\
\hline Coeficiente Motor Global (CM) & $67,77 \pm 11,30^{*}$ & $62,16 \pm 9,41^{*}$ \\
\hline Classe Locomotora (LO) & $64,76 \pm 13,09$ & $60,80 \pm 13,69$ \\
\hline Classe Controle de Objetos (CO) & $65,35 \pm 14,64^{*}$ & $55,25 \pm 14,88^{*}$ \\
\hline
\end{tabular}


TABELA 2 - Matriz de correlações de Pearson nas variáveis do questionário de ansiedade (IDATE-C) e de ${ }^{*} p<0.05 ;{ }^{* *} p<0.01$ desempenho no TGMD-2 nas duas condições experimentais.

\begin{tabular}{|c|c|c|c|c|c|c|c|c|c|c|c|c|}
\hline & 空 & 蛋 & 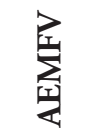 & $\underset{\substack{0\\
}}{0}$ & $\begin{array}{l}0 \\
\stackrel{U}{Z} \\
\end{array}$ & $\sum_{\text {至 }}^{0}$ & $\sum_{0}^{i}$ & ?] & $\frac{\overrightarrow{1}}{0}$ & 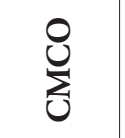 & ᄋ్త & $\begin{array}{l}0 \\
0 \\
0\end{array}$ \\
\hline AEIFV & - & & & & & & & & & & & \\
\hline ATIFV & $-0,20$ & - & & & & & & & & & & \\
\hline AEMFV & $0,60^{* *}$ & $-0,25$ & - & & & & & & & & & \\
\hline AEICO & $0,48^{* *}$ & $-0,32$ & $0,36^{*}$ & - & & & & & & & & \\
\hline ATICO & $-0,10$ & 0,13 & $-0,05$ & $-0,06$ & - & & & & & & & \\
\hline AEMCO & 0,34 & $-0,10$ & $0,37^{*}$ & $0,73^{* *}$ & $-0,07$ & - & & & & & & \\
\hline CMFV & $-0,13$ & $-0,02$ & 0,08 & $-0,01$ & 0,28 & $-0,17$ & - & & & & & \\
\hline LOFV & $-0,28$ & $-0,08$ & 0,03 & $-0,16$ & 0,33 & $-0,17$ & $0,76^{* *}$ & - & & & & \\
\hline OBFV & $-0,03$ & 0,11 & 0,16 & $-0,12$ & $0,36^{*}$ & $-0,26$ & $0,78^{* *}$ & $0,54^{* *}$ & - & & & \\
\hline $\mathrm{CMCO}$ & $-0,01$ & $-0,03$ & 0,03 & $-0,01$ & 0,26 & 0,13 & $0,50^{* *}$ & $0,34^{*}$ & $0,37^{*}$ & - & & \\
\hline LOCO & $-0,15$ & 0,04 & 0,04 & $-0,11$ & 0,19 & 0,01 & $0,38^{*}$ & $0,45^{* *}$ & $0,44^{* *}$ & $0,73^{* *}$ & - & \\
\hline OBCO & 0,26 & $-0,02$ & $0,38^{*}$ & $-0,02$ & $0,36^{*}$ & 0,12 & $0,38^{*}$ & $0,38^{*}$ & $0,53^{* *}$ & $0,73^{* *}$ & $0,58^{* *}$ & - \\
\hline
\end{tabular}

Quanto à normatização dos valores de desempenho no TGMD-2 sugerida pelo manual ${ }^{6}$, as frequências dos níveis do desenvolvimento motor nas duas condiçôes (TABELA 2) também foram analisadas por meio de um teste qui-quadrado, o qual indicou diferença significativa tanto na condição
$\mathrm{FV}[\chi 2(2)=13,61 ; \mathrm{p}=0,001]$, quanto na condição FO $[\chi 2(2)=40,52 ; \mathrm{p}=0,0001]$. O nível "Muito Pobre" apresentou frequências significativamente maiores do que os outros dois níveis ("Pobre" e "Abaixo da Média") tanto na condição FV quanto na condição FO.

TABELA 3 - Frequências dos níveis nos níveis de desenvolvimento motor nas duas condições experimentais.

\begin{tabular}{lccc}
\hline Nível desenvolvimento & FV & FO & Total \\
\hline Muito Pobre & 20 & 27 & 47 \\
\hline Pobre & 5 & 3 & 8 \\
\hline Abaixo da Média & 6 & 1 & 7 \\
\hline Total & 31 & 31 & 62 \\
\hline
\end{tabular}

\section{Discussão}

Efeito do conhecimento sobre a presença da filmadora no desempenho motor global de crianças

Os resultados indicaram diferenças significativas entre os desempenhos nas duas condiçóes, com superioridade para FV. Especificamente, o desempenho nas habilidades de controle de objeto (com impacto no quociente motor geral) foi superior quando as crianças realizaram as tarefas na presença da filmadora. Não foram detectadas diferenças de desempenho entre as condições nas habilidades de locomoção.

As explicaçóes para esses resultados podem ser alicerçadas em argumentos instrucionais e motivacionais. Para garantir que a criança visualizasse a filmadora na situação FV, antes do início do teste TGMD-2, a criança foi alertada para a presença da mesma. A hipótese relativa a esse ponto estabeleceu que as crianças apresentariam pior desempenho motor na situação $\mathrm{FV}$, pois sofreriam pressão com a informação de que suas ações estariam sendo 
gravadas. Entretanto, os resultados apontaram na direçấo contrária. $\mathrm{O}$ melhor desempenho na situação FV indica que o conhecimento sobre a filmadora pode ter desencadeado algum fator que influenciou positivamente o desempenho no teste. No TGMD-2, as crianças recebem do pesquisador instrução verbal e demonstração sobre como realizar as habilidades motoras ${ }^{6}$. No presente estudo, além dessas informaçôes, as crianças receberam a instrução adicional sobre a presença da filmadora, a qual pode ter agido como instrução motivacional.

Motivação é um processo ativo, intencional e dirigido a uma meta e depende da interação de fatores pessoais (intrínsecos) e ambientais (extrínsecos) ${ }^{26}$. $\mathrm{Na}$ presente pesquisa, o fator intrínseco seria a predisposiçáo para realizar o teste, enquanto o fator extrínseco seria a instrução dada pelos pesquisadores sobre a presença da filmadora. Embora limitada as habilidades motoras de controle de objeto, a realização do teste aliada à instruçáo sobre a presença da filmadora pode ter potencializado a vontade própria de realizar com mais afinco (autodeterminação). Com base na teoria da autodeterminação (TAD) $)^{27-32}$ a necessidade de se sentir competente e autônomo pode ter sido ampliada com o conhecimento da presença da filmadora, ou seja, com um fator que conferiu formalidade à situação. $\mathrm{O}$ prazer inerente em realizar as habilidades do teste ilustra que as crianças estavam bastante motivadas - embora não tenha sido objeto de controle objetivo, pôde-se observar o entusiasmo que as crianças demonstravam no ambiente de pesquisa. Assim, pode-se atribuir à motivaçáo o sentimento positivo e consequente envolvimento ótimo na realização das habilidades.

O melhor desempenho na situaçáo de filmadora visível ocorreu nas habilidades de controle de objeto. O controle de objeto envolve a coordenação de múltiplos membros conjuntamente à manipulação de um implemento e, talvez por essa maior complexidade em relação a habilidades locomotoras, a situação FV tenha causado um maior efeito de "exibicionismo" por parte das crianças, juntamente com o senso de competitividade muito comum em meninos. Sem relações com a situação $\mathrm{FV}$ ou $\mathrm{FO}$, estudos de comparação entre sexos encontraram que meninos obtiveram melhores resultados comparados às meninas no subteste de controle de objeto ${ }^{1,33,34}$. De fato, no cotidiano, meninos tendem a vivenciar com mais frequência atividades de manipulação mais "globais" (jogar futebol, subir em árvores, escalar paredes e brincadeiras turbulentas) em comparação às meninas, que são mais incentivadas a praticarem atividades de manipulação com predomínio de controle mais fino (brincadeiras de cozinha e de vestir e manipular objetos). Para estes estudos, o melhor desempenho nas habilidades de controle de objeto pode estar também relacionado a aspectos culturais, já que meninos são mais estimulados pelos pais, professores e sociedade a praticarem atividades físicas de várias modalidades esportivas e culturais desde pequenos.

A motivação intrínseca geradora de sentimento positivo e engajamento na realização das habilidades do TGMD-2 pelas crianças remete à teoria do fluxo ${ }^{35}$, segundo a qual a relação entre o nível do desafio e o nível de habilidade proporciona três dimensões: 1) se o desafio está em um nível alto e as habilidades em um nível baixo, o indivíduo experimenta ansiedade; 2) se o desafio está em um nível baixo e as habilidades em um nível alto, o indivíduo experimenta tédio e apatia; 3) se desafio e habilidade estão em níveis ótimos, o indivíduo experimenta o fluxo. Na presente pesquisa, considerando a novidade do teste como um desafio alto e o desempenho no teste como "muito pobre" (habilidade baixa - vide resultados normativos já descritos), podemos descartar, dentre as dimensôes apresentadas, a segunda opção. À primeira vista, há inclinação para acomodar os resultados na primeira dimensão "se o desafio está em um nível alto e as habilidades em um nível baixo, o indivíduo experimenta ansiedade". Todavia, os valores da ansiedade indicaram escores baixos; em uma escala de 20 a 60 pontos, as crianças obtiveram ansiedade-traço média de 33,5 pontos $(33,6$ e 33,1) e ansiedade-estado média de 31,05 pontos $(32,0$; 31,5; 30,8 e 29,9). Esses resultados permitem descartar também a primeira dimensão e considerar a possibilidade de as crianças terem operado na terceira dimensão. A objeção a essa hipótese é o desempenho considerado "muito pobre" segundo a normatização do teste. Então, parece ter havido se náo uma experiência de fluxo, uma experiência próxima ao fluxo ${ }^{36,37}$.

Outra forma de discutir esses resultados é entender que apesar do teste indicar que as crianças estão com desenvolvimento nas habilidades motoras básicas no nível "muito pobre", pode ser que na perspectiva da criança isso não seja considerado. Há duas situações que podem atuar em conjunto ou separado. $\mathrm{Na}$ primeira a criança não considera a forma com que realiza a tarefa, ou seja, dada que as experiências anteriores não geraram uma percepção da criança sobre os padróes de execução mais avançados, elas náo consideram esta forma no momento da realização da tarefa, e, portanto, percebem-se competentes. 
Vale enfatizar que, se nenhuma criança realiza o padrão de execução mais avançado, esse critério pode não se aplicar para as crianças. $\mathrm{O}$ segundo aspecto é que as crianças podem apenas considerar o resultado da ação - por exemplo, no tempo gasto para correr a distância, ou acertar a parede com a bola rebatida. Com isso, a forma de execução - aspecto que é considerado na avaliação no TGMD-2 - pode não ter sido importante para as crianças. Estas duas possibilidades em conjunto ou separadas permitem dizer que as crianças não se importam com o padrão de execução, tampouco as crianças em estágios mais avançados de desenvolvimento. Logo, o nível de habilidade motora percebido e real diferem, fato que tem sido descrito como falta de acurácia ${ }^{38}$. As crianças podem perceber-se motoramente competentes e, assim, dada a novidade do teste, podem se considerar em estados próximos ao fluxo. Vale lembrar que a filmadora pode ter sido percebida pela criança como o aspecto que tornou o desafio no nível ótimo ela já realiza as habilidades motoras de controle de objetivo, mas a filmadora potencializou o nível do desafio. Estas consideraçóes ajudam a elaborar uma hipótese explicativa para os resultados, mas ela apenas se estabelece em termos de proposição, pois se faz necessário obter o nível de competência motora percebida da criança.

Provavelmente, a título de especulação, o desafio do teste TGMD-2 tenha ultrapassado as habilidades das crianças, mas não a ponto de ter repercutido na ansiedade, mas de ter levado as crianças para níveis ótimos de ativaçãa ${ }^{35}$. A ativação cortical é denominada arousal, um estado muito próximo ao fluxo e caracterizado por desafio alto e habilidade moderada. A teoria do nível ótimo de ativação, conhecida também como teoria do " $U$ " invertido, sustenta que com baixos níveis de ativação, o desempenho de tarefas fica abaixo do padrão, porém à medida em que a ativação aumenta, ocorre a melhora do desempenho até uma faixa ideal, não podendo essa ativação, seja qual for, ser excessiva, pois acarretará nova queda de desempenho $0^{39-41}$. Em outras palavras, o arousal não pode ser nem baixo e nem alto, mas em um ponto médio para que o desempenho seja otimizado. Avaliase que as crianças do presente estudo executaram as tarefas do TGMD-2 com níveis ótimos de arousal, em que pese o fato de isso não ter sido mensurado objetivamente. Observou-se, sem qualquer controle experimental, durante a coleta, que na execução das habilidades de controle de objeto as crianças ficavam visivelmente mais eufóricas e empenhadas pelo fato de as habilidades envolverem a utilização da bola. Aliás, o fator "bola" tem sido aventado em outros estudos como candidato mais forte para aumentar a motivação para realizar as habilidades de controle de objeto ${ }^{22,23}$.

\section{Ausência de correlaçóes entre escores do TGMD-2 e escores de ansiedade}

No que se refere à hipótese secundária de que a situação com a presença da filmadora provocaria elevação dos níveis de ansiedade, não foram encontradas relaçóes significativas entre os escores (parciais e total) de desempenho no teste TGMD-2 e os escores de ansiedade em quaisquer dos momentos ou dos tipos de ansiedade (traço e estado). Esse achado corrobora o estudo de Romanholo et al. ${ }^{9}$, no qual não foram encontradas relaçóes entre variáveis de estresse infantil e desempenho de habilidades motoras grossas. Parece então que a presença da filmadora não se configurou em um aspecto relevante para causar impactos nos níveis de ansiedade traço e estado autorrelatados no questionário. Outro aspecto importante que devemos levar em conta é que, hoje em dia, com o avanço da tecnologia e a facilidade de acesso a objetos eletro-eletrônicos (celulares com filmadoras, mini-filmadoras, videogames), as crianças acabam expondo-se com maior frequência a situaçóes de gravação ou escaneamento corporal, o que teoricamente as torna menos inibidas e até mais motivadas diante de filmadoras. Estudos futuros podem avançar a análise de estados emocionais para além do autorrelato, como, por exemplo, a mensuração objetiva de parâmetros psicofisiológicos com aparelhos de resposta galvânica da pele, o qual, por meio de condutância elétrica da pele, quantifica estados emocionais que refletem ansiedade.

\section{Classificaçáo do desempenho motor das crianças segundo a normatizaçáo do TGMD-2}

Segundo a normatização dos valores de desempenho no TGMD sugerida pelo manual do TGMD- $2^{6}$, chama a atenção a alta frequência de crianças com baixos níveis de desenvolvimento motor. Nenhum valor foi classificado como "Na Média" ou "Superior". Todos os valores obtidos estiveram nas classificaçóes "Abaixo da Média", "Pobre" ou "Muito Pobre". Ainda mais marcante, os testes estatísticos apontaram que em ambas as condições (FV e FO) o nível "Muito Pobre" apresentou frequências significativamente maiores do que o nível "Pobre" e "Abaixo da Média". Esses achados corroboram outros estudos realizados em países de língua portuguesa e inglesa. O fraco 
desempenho no teste pode estar relacionado ao nível de desafio motor que as crianças são expostas nos dias de hoje. A "navegação" na internet, a assistência à televisão e o uso de jogos eletrônicos têm sido apontados por diversos autores como alguns dos principais obstáculos para a prática da atividade física na infância e na adolescência ${ }^{41-43}$. Por exemplo, em trabalho sobre atividade física, recreio escolar e desenvolvimento motor de crianças portuguesas com a utilização do TGMD-2 e do KTK (teste de coordenação motora), também foram detectados escores baixos em ambos os testes ${ }^{33}$. Da mesma forma, em investigação com crianças brasileiras por meio do TGMD-2, classificaram-nas igualmente com desempenho total "Muito Pobre"24. Ademais, esse mesmo nível de classificação no TGMD-2 foi apresentado por crianças com prática sistemática de atividades físicas ${ }^{42}$.

O teste TGMD-2 foi concebido e desenvolvido nos Estados Unidos da América por $\mathrm{ULRICH}^{6}$ que provavelmente utilizou habilidades motoras populares da cultura daquele país. Sabe-se que os esportes de maior tradição nos Estados Unidos da América são o beisebol, o basquetebol e o futebol americano. Assim, as habilidades de controle de objeto - como quicar e receber (basquetebol), arremessar e rebater (beisebol) e chutar (futebol americano) - foram provavelmente incluídas no teste por serem oriundas dessas modalidades. Em sociedades nas quais essas modalidades não são tão populares (como no Brasil), o desempenho no teste pode ser influenciado pela inexperiência prévia das crianças. Vale ressaltar que a questão que se torna importante diz respeito à inexperiência na forma de execução, e não necessariamente na ação motora. As crianças no Brasil podem até realizar tais tarefas motoras, mas não considerando os aspectos qualitativos que o teste apresenta, este seria o aspecto que nossas crianças não estão acostumadas ou são inexperientes, ainda mais se considerado que muitos professores não entendem que são importantes de serem ensinados nas aulas de clubes ou das escolas.

\title{
Agradecimentos
}

Agradecimento a CAPES (Coordenação de Aperfeiçoamento de Pessoal de Nível Superior) pelo auxílio à pesquisa através da bolsa de Mestrado.

\begin{abstract}
Camera awareness, anxiety levels, and global motor performance in children

The purpose of this study was to investigate the effect of camera awareness on the performance of fundamental motor skills and its relationship to levels of anxiety in children. Thirty-one boys aged between seven and nine years performed six locomotor and six object control skills of Ulrich's Test of Gross Motor Development in two conditions, with $\mathrm{x}$ without camera awareness. The Spielberger's State-Trait Anxiety Inventory was used to measure anxiety levels before and during the test. Each participant was tested on each condition, with a three-month interval between them. Student's t-tests for paired samples indicated that the children who were aware of the camera showed higher scores in the object control skills and in the general motor index. On both conditions, the chi-square test indicated that the majority of children were "very poor" regarding global motor development. No significant correlations were found between anxiety and motor performance. The findings were discussed in the light of theories of motivation for performance, focusing self-determination, flow and arousal.
\end{abstract}

KEYWORDS: Motor skill; Anxiety; TGMD-2; Children. 


\section{Referências}

1. Abiko RH, Caruzzo NM, Bim RH, Nazario PF, Lopes VJL. Avaliação do desempenho motor de crianças de 6 a 9 anos de idade. Cinergis. 2013;13(3):21-6.

2. Krebs RJ, Duarte MG, Nobre GC, Nazario PF, Santos JLO. Relação entre escores de desempenho motor e aptidão física em crianças com idades entre 7 e 8 anos. Rev Bras Cineantropom Desempenho Hum. 2011;13(2):94-9.

3. Marramarco CA, Krebs RJ, Valentini NC, Ramalho MHDS, Santos JOL, Nobre GC. Crianças desnutridas pregressas, com sobrepeso e obesas apresentam desempenho motor pobre. Rev Educ Fís/UEM. 2012;23(2):175-82.

4. Breslin CM, Rudisill ME. The effect of visual supports on performance of the TGMD-2 for children with autism spectrum disorder. Adapt Phys Activ Q. 2011;28(4):342-53.

5. Pang AW-Y, Fong DT-P. Fundamental motor skill proficiency of Hong Kong children aged 6-9 years. Res Sports Med. 2009;17(3):125-44.

6. Ulrich DA. Test of gross motor development: examiner's manual. Austin: Pro-ED; 2000.

7. Valentini NC. Validity and reliability of the TGMD-2 for Brazilian children. J Mot Behav. 2012;44(4):275-80.

8. Beltrão NB, Meira Júnior CM, Souza LV, Cunha AEV, Cattuzzo MT. Desempenho motor de crianças extrovertidas e introvertidas. Motricidade. 2012;8(2):993-8.

9. Romanholo RA, Heydrich V, Almeida AM, Coelho EM, Carvalhal MI. Análise da relação entre a maturação biológica e estresse na coordenação motora grossa em escolares de 5 a 10 anos. Rev Bras Ciênc Mov. 2012;20(2):91-7.

10. Vieira LF, Teixeira CA, Silveira JMD, Teixeira CL, Oliveira Filho A, Rorato WR. Crianças e desempenho motor: um estudo associativo. Motriz. 2009;15(4):804-9.

11. Villwock G, Valentini NC. Percepção de competência atlética, orientação motivacional e competência motora em crianças de escolas públicas: estudo desenvolvimentista e correlacional. Rev Bras Educ Fís Esporte. 2007;21(4):245-57.

12. Bokums RM, Meira Júnior CM, Neiva JFO, Oliveira T, Maia JF. Self-controlled feedback and trait anxiety in motor skill acquisition. Psychology. 2012;3(5):406-9.

13. Schmidt RA, Wrisberg CA. Aprendizagem e performance motora: uma abordagem da aprendizagem baseada na situação. Porto Alegre: Artmed; 2001.

14. Weinberg RS, Gould D. Foundations of sport and exercise psychology. 6a ed. Champaign: Human Kinetics; 2014.

15. Wrisberg CA. Sport skill instruction for coaches. Champaign: Human Kinetics; 2007.

16. Spielberger CD. Anxiety: current trends in theory and research. Oxford: Elsevier; 1972.

17. Eysenck MW, Calvo MG Anxiety and performance: the processing efficiency theory. Cogn Emot. 1992;6(6):409-34.

18. Eysenck MW, Derakshan N, Santos R, Calvo MG. Anxiety and cognitive performance: attentional control theory. Emotion. 2007;7(2):336-53.

19. Calvo MG, Ramos PM. Effects of test anxiety on motor learning: the processing efficiency hypothesis. Anxiety Research. 1989;2(1):45-55.

20. Biaggio A, Spielberger CD. Inventário de ansiedade traço-estado-IDATE-C: manual para a forma experimental infantil em português. Rio de Janeiro: Centro Editor de Psicologia Aplicada; 1983.

21. Thomas J, Nelson J, Silverman S. Métodos de pesquisa em atividade física. Porto Alegre: Artmed; 2012.

22. Tani G, Meira Júnior C, Oliveira JA, Basso L, Souza JA, Prista A, et al. Crescimento, aptidão física e coordenação motora de crianças de Muzambinho: os dois primeiros anos de estudo. São Paulo: Escola de Educação Física e Esporte da Universidade de São Paulo; 2007.

23. Basso L, Souza CJF, Araújo UO, Bastos FH, Bianchi TT, Meira Júnior CM, et al. Olhares distintos sobre a noção de estabilidade e mudança no desempenho da coordenação motora grossa. Rev Bras Educ Fís Esporte. 2012;26(3):495-509.

24. Valentini NC, Barbosa MLL, Cini GV, Pick RK, Spessato BC, Balbinotti MAA. Teste de desenvolvimento motor grosso: validade e consistência interna para uma população gaúcha. Rev Bras Cineantropom Desenvolvimento Hum. 2008;10(4):399-404.

25. Villwock GDMC. O estudo desenvolvimentista da percepção de competência atlética, da orientação motivacional, da competência motora e suas relaçóes em crianças de escolas públicas [dissertação]. Porto Alegre: Universidade Federal do Rio Grande do Sul, Escola de Educação Física; 2005.

26. Samulski, D. Psicologia do esporte: conceitos e novas perspectivas. Barueri: Manole; 2009.

27. Deci EL, Ryan RM. The empirical exploration of intrinsic motivational processes. In: Berkowitz L, editor. Advances in experimental social psychology. New York: Academic Press; 1980. Volume 13; p. 39-80.

28. Deci EL, Ryan RM. Intrinsic motivation and self-determination in human behavior. New York: Springer Science \& Business Media; 1985. 
29. Ryan RM. A motivational approach to self: integration in personality. In: Deci EL, organizador. Perspectives on motivation. Lincoln: University of Nebraska Press; 1991. p. 237-88.

30. Deci EL, Ryan RM. An overview of self-determination theory: an organismic-dialectical perspective. In: Deci EL, Ryan RM, editores. Handbook of self-determination research. Rochester: The University of Rochester Press; 2002. p. 3-33.

31. Deci EL. Interest and the intrinsic motivation of behavior. In: Krapp A, Hidi S, editores. The role of interest in learning and development. Mahwah: Lawrence Erlbaum Associates; 1992. p. 43-70.

32. Vallerand RJ. Deci and Ryan's self-determination theory: a view from the hierarchical model of intrinsic and extrinsic motivation. Psychological Inquiry. 2000;11(4):312-8.

33. Afonso GH, Freitas DL, Carmo JM, et al. Desempenho motor: um estudo normativo e criterial em crianças da região autônoma da Madeira, Portugal. Rev Port Ciênc Desporto. 2009;9(2-3):160-74.

34. Lopes LCO. Atividade física, recreio escolar e desenvolvimento motor: estudos exploratórios em crianças do $1^{\circ}$ ciclo de ensino básico [dissertação]. Braga: Universidade do Minho; 2006.

35. Csikszentmihalyi MA. Descoberta do fluxo: a psicologia do envolvimento com a vida cotidiana. Rio de Janeiro: Rocco; 1999.

36. Jackson SA, Eklund RC. The flow scales manual. Morgantown: Fitness Information Technology; 2004.

37. Miranda R, Bara Filho M. Construindo um atleta vencedor: uma abordagem psicofísica do esporte. Porto Alegre: Artmed; 2008.

38. Harter, S. The construction of the self: a developmental and sociocultural foundations. New York: Guilford Publications; 2015.

39. Martens R. Coaching young athletes. Champaign: Human Kinetics; 1981.

40. Weinberg R, Gould D. Fundamentos da psicologia do esporte e do exercício. Porto Alegre: Artmed; 2001.

41. Zajong RB. Social facilitation. Ann Arbor: Research Center for Group Dynamics, Institute for Social Research of the University of Michigan; 1965.

42. Alves JGB. Atividade física em crianças: promovendo a saúde do adulto. Rev Bras Saúde Matern Infant. 2003,3(1):5-6

43. Brauner LM, Valentini, NC. Análise do desempenho motor de crianças participantes de um programa de atividades físicas. Rev Educ Fís/UEM. 2009;20(2):205-16.

ENDEREÇO

Fabiana Monteiro Bassi

Escola de Artes, Ciências e Humanidades da

Universidade de São Paulo

Av. Arlindo Bettio, 1.00o - Jardim Keralux

03828-00o - São Paulo - SP - BRASIL

e-mail: fabibassi@gmail.com
Recebido para publicação: 22/03/2016

Aceito: 21/08/201 